\title{
Effect of Pharmaceutically Active Compound Nitroxoline on the Corrosion of Mild Steel in an Acidic Environment
}

\author{
R. Ganapathi Sundaram, G. Vengatesh, and M. Sundaravadivelu \\ Department of Chemistry, The Gandhigram Rural Institute-Deemed University, Gandhigram, Tamil Nadu 624 302, India
}

Correspondence should be addressed to M. Sundaravadivelu; msundargri@gmail.com

Received 11 April 2016; Accepted 25 July 2016

Academic Editor: Jolanta N. Latosinska

Copyright (C) 2016 R. Ganapathi Sundaram et al. This is an open access article distributed under the Creative Commons Attribution License, which permits unrestricted use, distribution, and reproduction in any medium, provided the original work is properly cited.

The effect of Nitroxoline, antibiotic drug, was tested as a corrosion inhibitor for mild steel (MS) in an acidic environment by chemical method (mass loss measurement) and electrochemical methods such as electrochemical impedance spectroscopy and potentiodynamic polarization. The surface morphology of mild steel was investigated by scanning electron microscopy, energy dispersive X-ray spectroscopy, and atomic force microscopy techniques. From the chemical and electrochemical methods, the resistance of corrosion was increased with the addition of Nitroxoline concentration. Tafel curves indicate that the pharmaceutically active compound is a cathodic type inhibitor. An adsorption of Nitroxoline on the surface of mild steel was obeyed by Langmuir isotherm. SEM, EDX, and AFM techniques prove the adsorption process. All the obtained results confirmed that the investigated compound Nitroxoline acts as a good inhibitor for the corrosion of mild steel in an acidic environment.

\section{Introduction}

Corrosion is a slow but dangerous process of materials. Low carbon content iron especially mild steel is one of the most important materials, which has the wide range of structural and industrial applications. However, the major drawback of using mild steel is its dissolution in an acidic environment [1]. As it is impossible to eliminate the corrosion, hence the control of corrosion is rather than its prevention which will lead to effective engineering. In order to reduce the rate of dissolution of metal, the use of inhibitor is one of the best and economical methods. In most of the acid corrosion, the inhibitors are organic compounds which contain heteroatoms such as nitrogen, sulphur, oxygen, phosphorous, and aromatic rings $[2,3]$. This kind of inhibitors reduces or prevents the corrosion rate by (i) adsorption of ions/molecules onto mild steel surface, (ii) increasing or decreasing the anodic and/or cathodic reactions, (iii) decreasing the diffusion rate for reactants to the surface of the metal, and (iv) decreasing the electrical resistance of the metal surface [4]. Nowadays several inhibitors are used to reduce the rate of corrosion in mild steel but unfortunately they are environmentally toxic, with high cost, and easily unavailable. Therefore, the choice of inhibitor is very important. Moreover, the investigated inhibitor is commercially available, with low cost, and easily soluble in acid media and is environmentally safe, because it acts as an antibiotic and also has been used in an anticancer setting. In the view of these facts, Nitroxoline was chosen as inhibitor for corrosion studies. In this work, the effect of pharmaceutically active compound Nitroxoline on the corrosion of mild steel in $1 \mathrm{M}$ sulphuric acid solution was studied. The corrosion resistance was evaluated by using polarization, impedance spectroscopy, and mass loss measurements. The adsorption of Nitroxoline on the surface of mild steel was confirmed by SEM, EDX, and AFM techniques.

\section{Material and Experimental Procedure}

2.1. Preparation of Mild Steel Specimen. The commercially available mild steel rod is obtained from market, which was mechanically cut into $3.5 \times 1.5 \times 0.2 \mathrm{~cm}$ dimensions with 1 hole in the upper edge of each specimen for chemical (mass loss) measurements and $1.0 \times 1.0 \times 0.2 \mathrm{~cm}$ dimensions for surface morphology techniques. For an electrochemical investigation, $1.0 \mathrm{~cm}^{2}$ area of the mild steel was exposed to the $100 \mathrm{~mL}$ of $1 \mathrm{M}$ sulphuric acid and the balance being covered by epoxy resin. The surfaces of the mild steel specimens 
TABLE 1: The elemental composition of the mild steel.

\begin{tabular}{lccccc}
\hline Elements & $\mathrm{Fe}$ & $\mathrm{Mn}$ & $\mathrm{C}$ & $\mathrm{P}$ & $\mathrm{S}$ \\
\hline Weight (\%) & 99.255 & 0.580 & 0.104 & 0.035 & 0.026 \\
\hline
\end{tabular}

were polished with various grades of emery papers and then degreased with AR grade acetone. Finally, it is dried in air drier before all the investigation. The elemental composition of the mild steel is presented in Table 1.

2.2. Preparation of Aggressive Solution. The aggressive medium (1 M sulphuric acid) was prepared with $97 \%$ analytical grade of sulphuric acid received from Sigma-Aldrich and double distilled water.

2.3. Preparation of Inhibitor Solution. The pharmaceutically active compound Nitroxoline was purchased from SigmaAldrich and used as a corrosion inhibitor in an acidic environment. The IUPAC name, chemical structure, and some other important details of the investigated inhibitor are given in Table 2. The preparation of various concentrations (50 to $300 \mathrm{ppm}$ ) of investigated inhibitor was done according to the standard method as described earlier [5].

2.4. Chemical Method: Mass Loss Measurements. The mass loss (chemical) measurement is a very basic and most widely acceptable method of corrosion inhibition assessment. In this method previously, weighed mild steel specimens are immersed for $3 \mathrm{hrs}$ in $100 \mathrm{~mL}$ of $1 \mathrm{M}$ sulphuric acid solution in various concentrations of both inhibitor solution and inhibitor free acid solution. After the corrosion test hours the mild steel specimens were taken out, washed, dried with air drier, and weighed accurately. Duplicate experiments were done in each (inhibitor and inhibitor free acid solution) and the mean value of the mass loss values was reported.

From the mass loss values the corrosion rate $(W)$ and inhibition efficiency (IE \%) were calculated according to the following equations:

$$
\text { C.R. }=W=\frac{m_{1}-m_{2}}{S t},
$$

where $m_{1}$ and $m_{2}$ are the mass of the polished mild steel and mass of the corroded mild steel, $S$ is the surface area of mild steel, $t$ is the time of immersion, and $W$ is the mass loss of the mild steel specimen

$$
\operatorname{IE}(\%)=\left[\frac{w_{0}-w_{i}}{w_{0}}\right] \times 100,
$$

where $w_{0}$ and $w_{i}$ are the corrosion rate of the absence and presence of Nitroxoline, respectively.

2.5. Electrochemical Method: AC Impedance Spectroscopy and Potentiodynamic Polarization Measurements. Electrochemical measurements including potentiodynamic polarization measurements and AC impedance spectroscopy measurements were done by $\mathrm{CH}$-Electrochemical analyzer model
$760 \mathrm{D}$ with CHI $760 \mathrm{D}$ software. The used electrochemical analyzer contains three electrodes that are working electrode (mild steel), auxiliary electrode (platinum), and reference electrode (saturated calomel electrode). Before starting the measurements, the working electrode was allowed to reach steady-state value of OCP. All the three electrodes were kept immersed in $1 \mathrm{M}$ sulphuric acid solution both in inhibitor free acid solution and in various concentrations of inhibitor. The measurements were carried out after 30 minutes of immersion time at room temperature.

Impedance spectroscopy measurements were carried out in the frequency range of $10,000 \mathrm{~Hz}$ to $0.1 \mathrm{~Hz}$ with $\mathrm{AC}$ impedance signal of $0.01 \mathrm{~V}$ amplitude. From this measurement, the impedance diagrams like Nyquist and Bode were plotted. The corrosion parameters such as charge transfer resistance $\left(R_{\mathrm{ct}}\right)$ and double layer capacitance $\left(C_{\mathrm{dl}}\right)$ were calculated from Nyquist plots. From the $R_{\mathrm{ct}}$ value, the inhibition efficiency of Nitroxoline in $1 \mathrm{M}$ sulphuric acid solution was determined by using the following equation:

$$
\mathrm{IE}(\%)=\left[\frac{R_{\mathrm{ct}}^{i}-R_{\mathrm{ct}}^{0}}{R_{\mathrm{ct}}^{i}}\right] \times 100,
$$

where $R_{\mathrm{ct}}^{i}$ and $R_{\mathrm{ct}}^{0}$ are the charge transfer resistance values of with and without Nitroxoline, respectively.

The potentiodynamic polarization curves (Tafel plots) were obtained by changing the electrode potential automatically from $-300 \mathrm{mV}$ cathodically to $+300 \mathrm{mV}$ anodically in respect to OCP with a scan rate of $0.1 \mathrm{mV} / \mathrm{s}$. From the polarization investigation, the inhibition efficiency was calculated from corrosion current density $\left(I_{\text {corr }}\right)$ values according to the following equation:

$$
\operatorname{IE}(\%)=\left[\frac{I_{\text {corr }}^{0}-I_{\text {corr }}^{i}}{I_{\text {corr }}^{0}}\right] \times 100,
$$

where $I_{\text {corr }}^{0}$ and $I_{\text {corr }}^{i}$ are the corrosion current density values of the absence and presence of Nitroxoline, respectively.

\subsection{Surface Morphology Studies}

2.6.1. SEM Analysis. The surface morphology of fresh mild steel specimen and uninhibited and inhibited mild steel specimens was analyzed by using JEOL/EO JSM-6390 model SEM.

2.6.2. EDX Analysis. The EDX system is also combined with a JEOL/EO JSM-6390 scanning electron microscopy. It is mainly used for the analysis of elements in the studied mild steel specimens.

2.6.3. AFM Analysis. AFM analysis is one of the major analyses of surface study, which is used for the further investigation in the formation of protective film on the surface of mild steel. The atomic force microscopy (AFM) "NT-MDT modular AFM" Ireland model is used to investigate the topography image of mild steel surface in absence and presence of optimum concentration of Nitroxoline. This analysis was carried out in Sathyabama University, Chennai, Tamil Nadu. 
TABLE 2: IUPAC name, chemical structure, active centre, molecular formula, and molecular weight of Nitroxoline.

IUPAC name of the inhibitor

TABLE 3: Inhibition efficiency values of various concentrations of Nitroxoline.

\begin{tabular}{|c|c|c|c|c|}
\hline Nitroxoline conc. (ppm) & Mass loss $\left(\mathrm{mg} \mathrm{cm}^{-2}\right)$ & Corrosion rate $\left(\mathrm{mm} \mathrm{y}^{-1}\right)$ & Surface coverage $(\theta)$ & $\begin{array}{c}\text { IE (\%) } \\
\eta\end{array}$ \\
\hline $\mathrm{H}_{2} \mathrm{SO}_{4}$ (blank) & 20.7 & 49.29 & - & - \\
\hline 50 & 6.8 & 16.19 & 0.6715 & 67.15 \\
\hline 100 & 5.9 & 14.05 & 0.7150 & 71.50 \\
\hline 150 & 4.7 & 11.19 & 0.7730 & 77.30 \\
\hline 200 & 3.2 & 7.62 & 0.8454 & 84.54 \\
\hline 250 & 2.3 & 5.48 & 0.8888 & 88.88 \\
\hline 300 & 1.3 & 3.10 & 0.9371 & 93.71 \\
\hline
\end{tabular}

\section{Results and Discussion}

3.1. Chemical Method: Mass Loss (ML) Studies. Table 3 gives the inhibition efficiency values of various concentrations of Nitroxoline for the corrosion of mild steel in $1 \mathrm{M}$ sulphuric acid solution. From the investigation, the inhibition efficiency was increased with the addition of Nitroxoline concentration. This is due to the strong interaction of Nitroxoline compound with mild steel surface that results in the adsorption of inhibitor molecule [6]. The nitrogen atoms can donate the $\pi$ electrons to the active sites of mild steel surface to increase the adsorption process and attain the maximum inhibition efficiency $(93.71 \%)$ at optimum $(300 \mathrm{ppm})$ concentration of the inhibitor [7]. Figures 1 and 2 represent the inhibition efficiency and corrosion rate of the studied pharmaceutically active compound. From Figure 1 the IE (\%) is increased with the addition of the inhibitor and Figure 2 shows the corrosion rate of mild steel decreases with the addition of active compound, which explains the formation of protective layer on the corroded surface. This study clearly indicates the mild steel surface is protected from the corrosive medium.

\subsection{Electrochemical Method}

3.2.1. AC Impedance Spectroscopy Studies. The AC impedance spectroscopy studies were investigated by varying the concentrations of Nitroxoline in $1 \mathrm{M}$ sulphuric acid at room temperature. From this study, the impedance diagrams such as Nyquist and Bode were obtained and shown in Figures 3(a) and 3(b). The impedance data such as $R_{\mathrm{ct}}, C_{\mathrm{dl}}$, and $\theta$ were obtained from Nyquist plot. The percentage of inhibition efficiency is determined from $R_{\mathrm{ct}}$ values according to the above-mentioned equation and all the impedance parameters are given in Table 4 . The impedance studies clearly indicate that the $R_{\mathrm{ct}}$ value increased and $C_{\mathrm{dl}}$ values decreased with

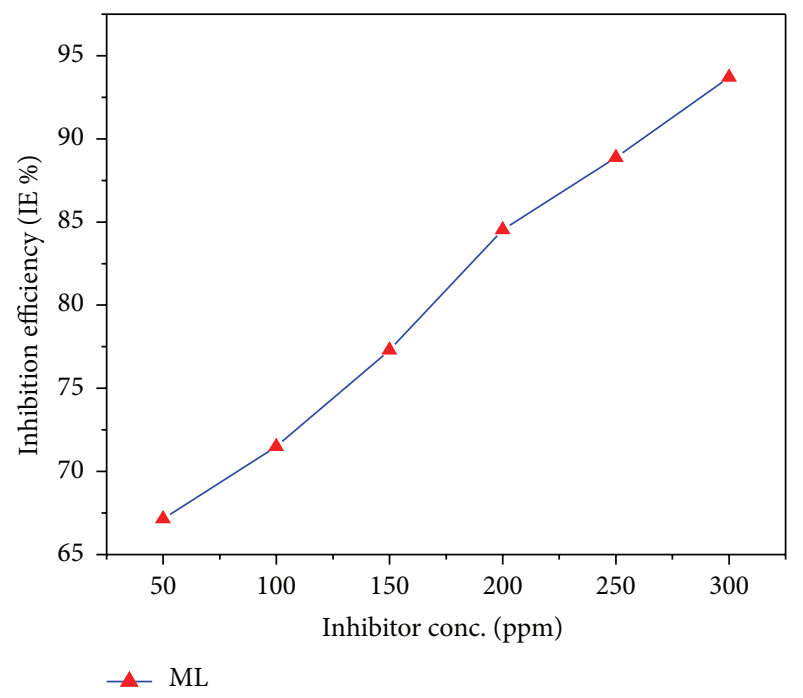

FIGURE 1: Inhibition efficiency plot for mild steel corrosion in $1 \mathrm{M}$ $\mathrm{H}_{2} \mathrm{SO}_{4}$ in the presence of Nitroxoline by mass loss study.

the addition of Nitroxoline concentration. The increase in the $R_{\mathrm{ct}}$ values with Nitroxoline concentrations indicates an increase in the surface coverage by the adsorption of inhibitor molecules on the mild steel, which resulted in the formation of protective film and an increase in inhibitor efficiency $[8,9]$. The thickness of the protective layer $\delta_{\text {inh }}$ was related to $C_{\mathrm{dl}}$ by the following equation:

$$
\delta_{\text {inh }}=\frac{\varepsilon_{0} \varepsilon_{r}}{C_{\mathrm{dl}}}
$$

where $\varepsilon_{0}$ is the dielectric constant and $\varepsilon_{r}$ is the relative dielectric constant. This decrease in $C_{\mathrm{dl}}$ values from 2823.2 to $64.26 \mu \mathrm{F} \mathrm{cm}^{-2}$ is due to the reduction in local dielectric 
TABLE 4: AC impedance spectroscopy parameters for mild steel corrosion in $1 \mathrm{M}$ sulphuric acid solution at various concentrations of the inhibitor.

\begin{tabular}{|c|c|c|c|c|c|}
\hline Nitroxoline conc. (ppm) & $Y_{\max }\left(\Omega \mathrm{cm}^{2}\right)$ & $R_{\mathrm{ct}}\left(\Omega \mathrm{cm}^{2}\right)$ & $C_{\mathrm{dl}}\left(\mu \mathrm{F} \mathrm{cm}^{-2}\right)$ & Surface coverage $(\theta)$ & $\begin{array}{c}\text { IE (\%) } \\
\eta\end{array}$ \\
\hline $\mathrm{H}_{2} \mathrm{SO}_{4}$ (blank) & 5.303 & 10.636 & 2823.2 & - & - \\
\hline 50 & 16.004 & 32.033 & 310.61 & 0.6680 & 66.80 \\
\hline 100 & 18.298 & 36.712 & 237.04 & 0.7103 & 71.03 \\
\hline 150 & 20.058 & 40.180 & 197.58 & 0.7353 & 73.53 \\
\hline 200 & 22.184 & 44.474 & 161.40 & 0.7608 & 76.08 \\
\hline 250 & 26.105 & 52.588 & 115.99 & 0.7977 & 79.77 \\
\hline 300 & 35.152 & 70.499 & 64.26 & 0.8491 & 84.91 \\
\hline
\end{tabular}

TABLE 5: Potentiodynamic polarization parameters for mild steel corrosion in $1 \mathrm{M}$ sulphuric acid solution at various concentrations of the inhibitor.

\begin{tabular}{|c|c|c|c|c|c|c|}
\hline Nitroxoline conc. (ppm) & $\beta_{a}(\mathrm{~V} / \mathrm{dec})$ & $\beta_{c}(\mathrm{~V} / \mathrm{dec})$ & $E_{\text {corr }}(\mathrm{mV} / \mathrm{SCE})$ & $I_{\text {corr }}\left(\mathrm{mA} / \mathrm{cm}^{2}\right)$ & $R(\mathrm{ohm})$ & $\begin{array}{c}\text { IE }(\%) \\
\eta\end{array}$ \\
\hline $\mathrm{H}_{2} \mathrm{SO}_{4}$ (blank) & 6.875 & 6.417 & -267 & 2.277 & 14 & - \\
\hline 50 & 6.453 & 6.569 & -345 & 0.9727 & 34 & 57.28 \\
\hline 100 & 7.347 & 7.063 & -266 & 0.7085 & 43 & 68.88 \\
\hline 150 & 6.156 & 7.164 & -290 & 0.6299 & 52 & 72.34 \\
\hline 200 & 6.871 & 7.298 & -301 & 0.4693 & 65 & 79.39 \\
\hline 250 & 7.472 & 7.261 & -361 & 0.4155 & 71 & 81.75 \\
\hline 300 & 9.096 & 8.378 & -299 & 0.2599 & 96 & 88.59 \\
\hline
\end{tabular}

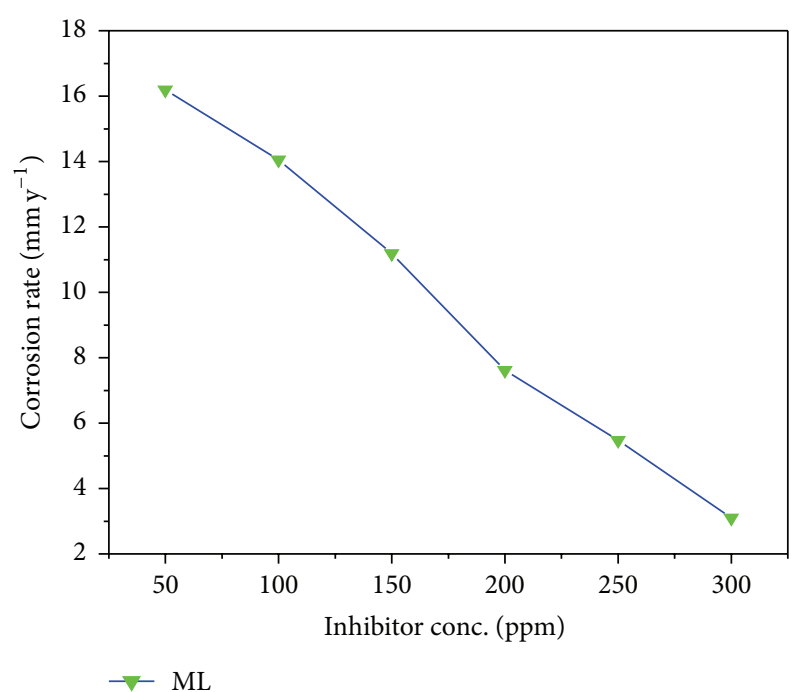

FIGURE 2: Plot of corrosion rate for mild steel in $1 \mathrm{M} \mathrm{H}_{2} \mathrm{SO}_{4}$ in the presence of Nitroxoline by mass loss study.

constant and/or an increment in the thickness of the electrical double layer [10]. Further, the thickness of the protective layer is based on the electronic structure of the studied inhibitor molecule. If the molecule contains more number of heteroatoms, the thickness of the layer is more protective. The studied inhibitor molecule contains nitrogen, oxygen, and fused benzene rings. Therefore it may donate a lone pair of electrons to the vacant "d" orbital of the metal atom and form a bond between the inhibitor molecule and the metal.

The decrease in $C_{\mathrm{dl}}$ values was due to the gradual replacement of water molecules by the adsorption of investigated inhibitor molecules at mild steel/solution interface, which led to the formation of protective film on the mild steel surface [1].

In Figure 3(b), the phase angle increases with increase in the investigated inhibitor concentration; this is due to the adsorption of inhibitor molecule on the surface of mild steel [11]. The obtained inhibition efficiency by this method has shown good agreement with the result obtained from mass loss method.

3.2.2. Potentiodynamic Polarization Studies. Figure 4 shows the Tafel curves of inhibition effect of various concentrations of Nitroxoline on mild steel in $1 \mathrm{M}$ sulphuric acid at room temperature. The obtained corrosion parameters from polarization studies are given in Table 5 . The $I_{\text {corr }}$ value of inhibitor free acid solution is $2.277 \mathrm{mV} / \mathrm{cm}^{2}$ but in the presence of optimum concentration of studied inhibitor $I_{\text {corr }}$ value is $0.260 \mathrm{mV} / \mathrm{cm}^{2}$, which indicates that the corrosion current density is remarkably decreased in the presence of investigated inhibitor. The inhibition efficiency of the studied inhibitor on the surface of mild steel is $57.3 \%$ to $88.6 \%$, respectively. From these studies the surface of working electrode is protected from the corrosive medium, with the addition of inhibitor concentration. It also indicates that the working electrode in the presence of inhibitors has a lower 


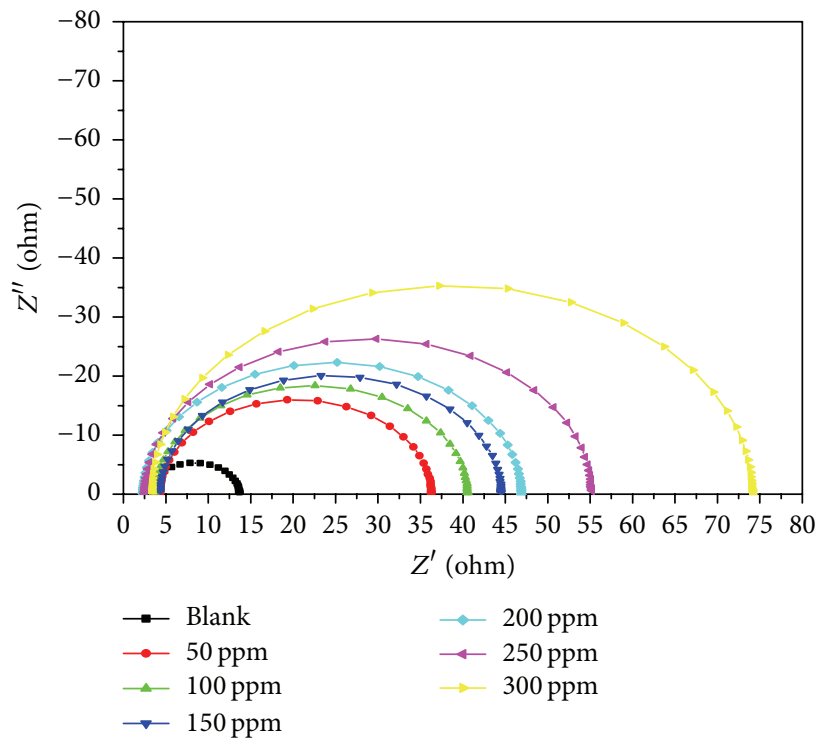

(a)

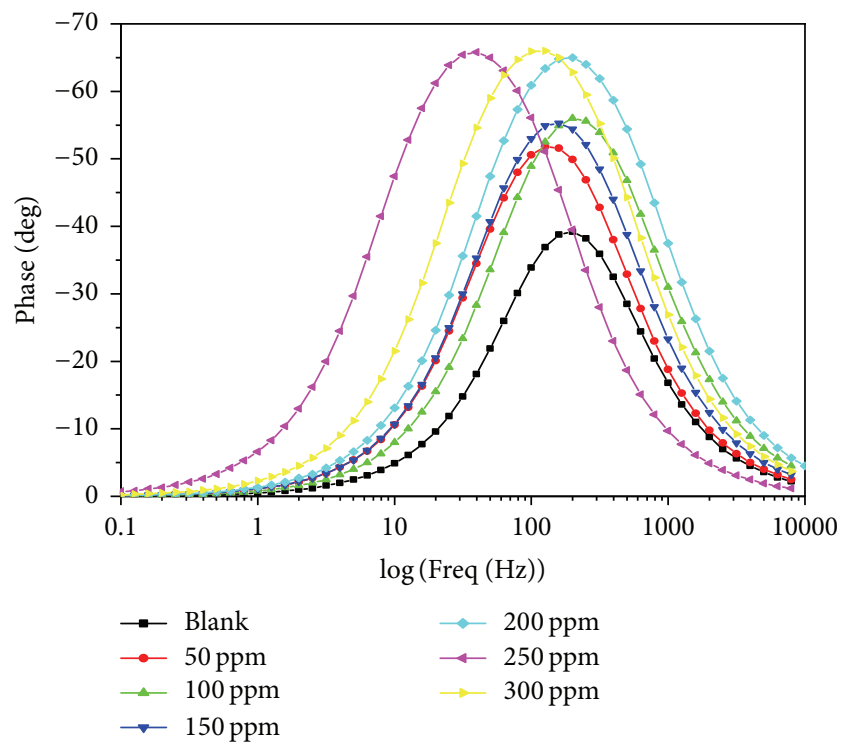

(b)

Figure 3: (a) AC impedance (Nyquist) plots for the corrosion of mild steel in $1 \mathrm{M} \mathrm{H}_{2} \mathrm{SO}_{4}$ with various concentrations of Nitroxoline. (b) AC impedance (Bode) plots for the corrosion of mild steel in $1 \mathrm{M} \mathrm{H}_{2} \mathrm{SO}_{4}$ with various concentrations of Nitroxoline.

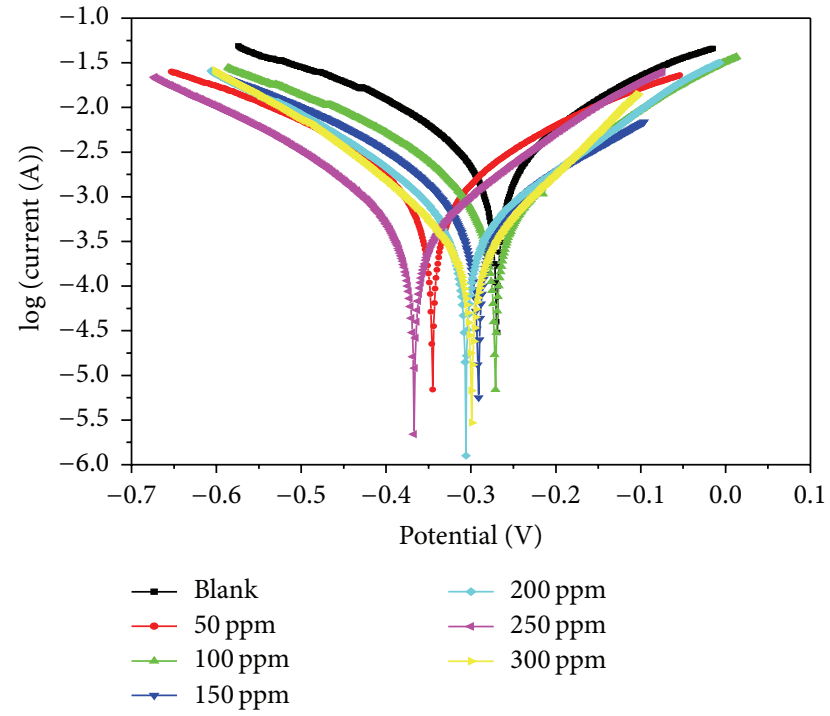

Figure 4: Potentiodynamic polarization (Tafel) plots for the corrosion of mild steel in $1 \mathrm{M} \mathrm{H}_{2} \mathrm{SO}_{4}$ with various concentrations of Nitroxoline.

$I_{\text {corr }}$ and better corrosion inhibition effect [12]. The decrease of corrosion current density may be explained by the action of inhibitor on both cathodic and anodic reactions [13]. But the Tafel curves clearly indicate that the studied inhibitor molecules are more adsorbed on cathodic sites. Generally, if the shift of $E_{\text {corr }}$ is $>85$ with respect to $E_{\text {corr }}$ of inhibitor free acid (blank) solution, the inhibitor can be viewed as cathodic or anodic type [14]. The maximum shift of $E_{\text {corr }}$ value of the investigated inhibitor is $94 \mathrm{mV}$; therefore it acts as a cathodic inhibitor for mild steel in $1 \mathrm{M}$ sulphuric acid solution [15].
3.3. Adsorption Isotherm Studies. The interaction between an inhibitor and the mild steel surface can be described by adsorption isotherm. This process is determined by using the surface coverage data and it plays an important role in the prediction of an adsorption isotherm. The degree of surface coverage $(\theta)$ is calculated by using the equation $\theta=\%$ $\mathrm{IE} / 100[16,17]$. The $\theta$ values obtained from mass loss studies, impedance studies, and polarization studies were tested with different types of adsorption isotherm at room temperature. Among the different types of adsorption isotherm studies, the Langmuir isotherm gives the best fit at room temperature. According to Langmuir adsorption isotherm, $\theta$ is related to $C_{\text {inh }}$ by the following equation:

$$
\frac{C_{\text {inh }}}{\theta}=\frac{1}{K_{\text {ads }}}+C_{\text {inh }},
$$

where $C_{\text {inh }}$ is the inhibitor concentration (ppm), $\theta$ is the degree of surface coverage, and $K_{\mathrm{ads}}$ is the adsorption equilibrium constant.

The $K_{\text {ads }}$ values can be calculated from the intercept lines on the $C_{\text {inh }} / \theta$ axis. This is related to $\Delta G_{\text {ads }}^{0}$ with the following equation:

$$
\Delta G_{\mathrm{ads}}^{0}=-R T \ln \left(55.5 K_{\mathrm{ads}}\right),
$$

where $R$ is the universal gas constant, $T$ is the absolute temperature, and 55.5 is the concentration of water in solution in $\mathrm{mol} \mathrm{L}^{-1}[10]$. The Langmuir adsorption isotherm was drawn by plotting $C_{\text {inh }} / \theta$ versus $C_{\text {inh }}$ for various concentrations of inhibitor and considering the $\theta$ values from ML method, EIS, and Tafel polarization method. The obtained graph was shown in Figure 5. The straight line obtained in the graph clearly shows that the investigated inhibitor obeys Langmuir adsorption isotherm. The obtained thermodynamic parameter values are given in Table 6 . Generally, the value of $\Delta G_{\text {ads }}^{0}$ 
TABLE 6: Thermodynamic parameters values obtained from Langmuir isotherm for the adsorption of Nitroxoline on mild steel in $1 \mathrm{M}$ sulphuric acid.

\begin{tabular}{lccc}
\hline Method & $R^{2}$ & $K_{\text {ads }}\left(10^{4} \mathrm{M}^{-1}\right)$ & $\Delta G_{\text {ads }}^{0}\left(\mathrm{~kJ} \mathrm{~mol}^{-1}\right)$ \\
\hline Mass loss & 0.9908 & 25.3192 & -18.26 \\
EIS & 0.9928 & 40.1632 & -19.42 \\
Tafel & 0.9922 & 22.9343 & -18.10 \\
\hline
\end{tabular}

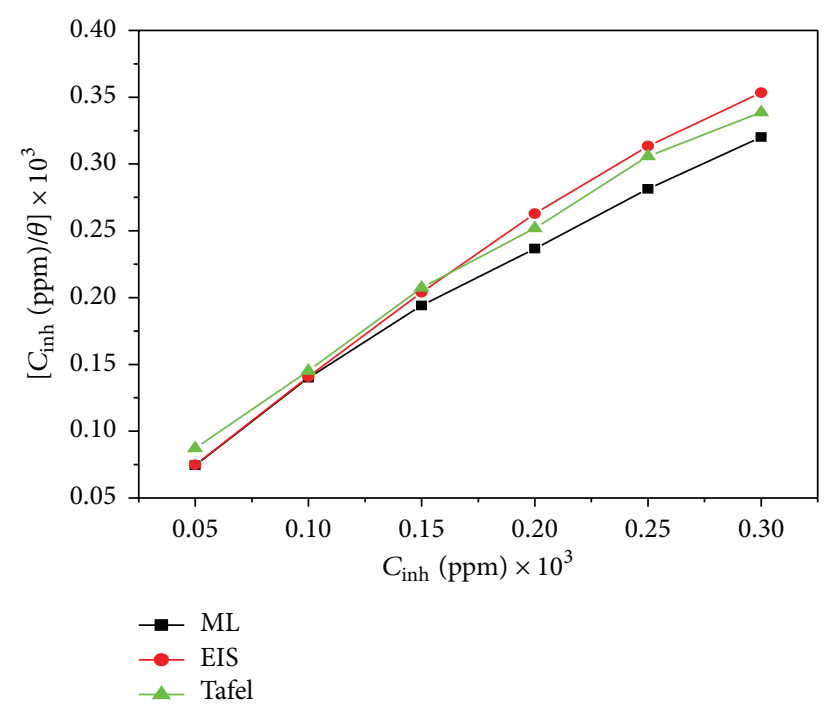

FIGURE 5: Langmuir plot (using ML, EIS, and Tafel results) for mild steel corrosion in $1 \mathrm{M} \mathrm{H}_{2} \mathrm{SO}_{4}$ in the presence of Nitroxoline.

less negative than $-20 \mathrm{~kJ} \mathrm{~mol}^{-1}$ signifies physisorption and the value more negative than about $-40 \mathrm{~kJ} \mathrm{~mol}^{-1}$ indicates chemisorptions [18]. From this study the calculated $\Delta G_{\text {ads }}^{0}$ value of the investigated inhibitor is less negative than $-20 \mathrm{~kJ} \mathrm{~mol}^{-1}$; therefore the process of inhibition is through physisorption and the adsorption process is spontaneous.

\subsection{Surface Morphology Studies}

3.4.1. SEM Analysis. The SEM images of fresh mild steel specimen, specimen in $1 \mathrm{M}$ acid, and specimen in inhibited (300 ppm inhibitor) $1 \mathrm{M}$ acid are shown in Figures 6(a)6(c). The investigation of the Figures 6(a)-6(c) reveals that the mild steel surface (Figure 6(b)) is damaged more in the absence of inhibitor and less in the presence of optimum concentration of inhibitor (Figure 6(c)) and the image shows a good protective film formation by the adsorbed inhibitor molecules on the mild steel surface [19].

3.4.2. EDX Analysis. The EDX images of fresh mild steel and uninhibited and inhibited mild steel with aggressive medium are shown in Figures $7(\mathrm{a})-7(\mathrm{c})$, respectively. Analysis of Figure 7(b) indicates the presence of iron, oxygen, carbon, and sulphur peaks, whereas the surface of inhibited mild steel Figure 7 (c) indicates the presence of iron, oxygen, carbon nitrogen, and sulphur peaks. In this analysis, new peak nitrogen is obtained in the plot (Figure $7(\mathrm{c})$ ). This is due to the adsorption of inhibitor molecules on the surface of mild steel. Further, there is a decrease in the percentage of iron (Table 7) in the inhibited mild steel surface with aggressive medium. This analysis also proves the adsorption of inhibitor molecules on the surface of mild steel.

3.4.3. AFM Analysis. Atomic force microscopy (AFM) is a powerful tool to investigate the surface topography at nano-to-micro scale and it is very useful to determine the protective film formation on metal and alloy surface in corrosion inhibition studies. AFM is an accepted method of roughness investigation of metals, alloys, and glasses [20]. The two-dimensional (2D) and three-dimensional (3D) AFM topography of fresh mild steel and mild steel in $1 \mathrm{M}$ $\mathrm{H}_{2} \mathrm{SO}_{4}$ solution without and with the presence of optimum concentration (300 ppm) of Nitroxoline are shown in Figures 8(a), 8(b), 9(a), 9(b), 10(a), and 10(b). The AFM parameters such as average roughness, root-mean-square roughness, maximum peak-to-peak height, and ten-point height values are summarized in Table 8.

In Figure 9(b), the mild steel surface contains number of bits and cavities, that is, severally damaged in $1 \mathrm{M} \mathrm{H}_{2} \mathrm{SO}_{4}$ solution compared to fresh mild steel in Figure 8(b) (without corrosive medium and inhibitor) and inhibited mild steel in Figure 10(b). Moreover, the average roughness of fresh mild steel and corroded mild steel (MS in $1 \mathrm{M} \mathrm{H}_{2} \mathrm{SO}_{4}$ ) was calculated to be 9.77 and $28.74 \mathrm{~nm}$, respectively. With the addition of optimum concentration $(300 \mathrm{ppm})$ of inhibitor, the average roughness of inhibited mild steel value was reduced to $12.01 \mathrm{~nm}$, which suggested that the protective film was formed on the surface of mild steel [21].

\section{Conclusions}

From the above investigations, the following points are concluded:

(i) The studied pharmaceutically active compound Nitroxoline acts as effective corrosion inhibitor for mild steel in sulphuric acid medium.

(ii) The corrosion inhibition effect was increased with the addition of Nitroxoline concentration.

(iii) The inhibitor gives maximum efficiency (93.71) at optimum concentration (300 ppm) of inhibitor.

(iv) Impedance spectroscopy study was used to investigate the mechanism of corrosion inhibition. It confirms that the investigated inhibitor follows adsorption mechanism.

(v) A Tafel polarization study reveals that the studied inhibitor acts as cathodic in nature.

(vi) The obtained values of $\Delta G^{0}$ in both methods (chemical and electrochemical) indicate that the inhibition process on the surface of mild steel is physisorption and the process is spontaneous.

(vii) SEM, EDX, and AFM studies confirmed the formation of protective film on the surface of mild steel. 


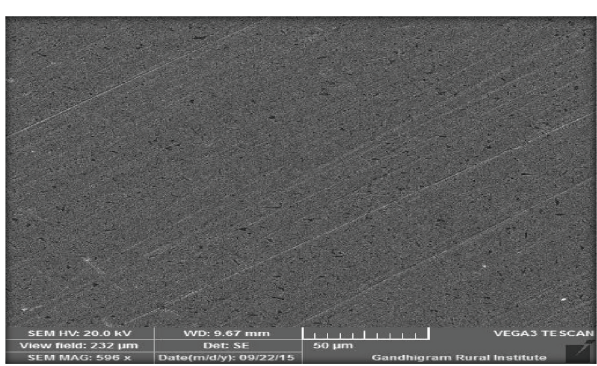

(a)

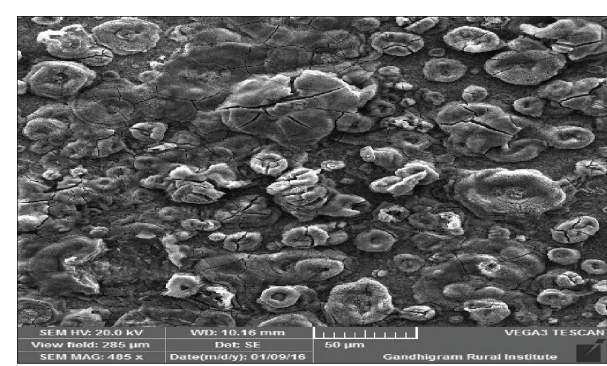

(b)

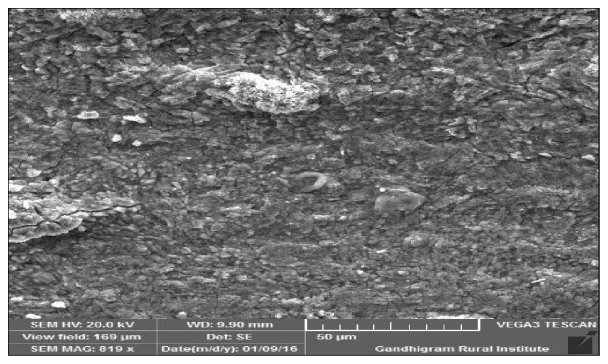

(c)

FIGURE 6: SEM images: (a) fresh mild steel, (b) mild steel in $\mathrm{H}_{2} \mathrm{SO}_{4}$, and (c) mild steel in $\mathrm{H}_{2} \mathrm{SO}_{4}$ with Nitroxoline.

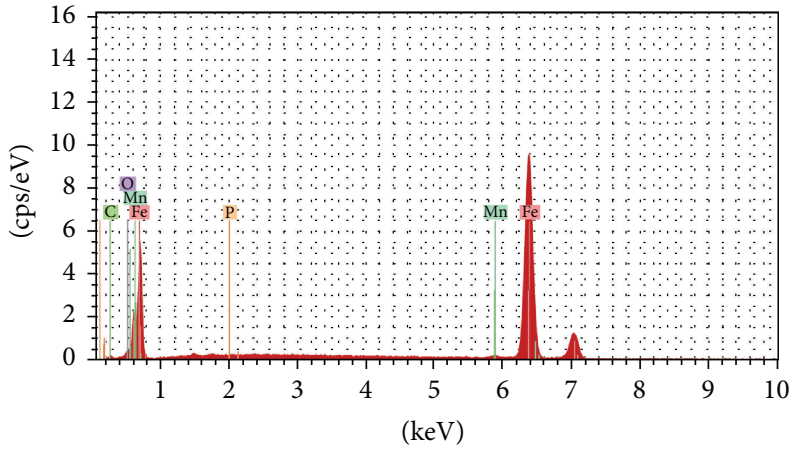

(a)

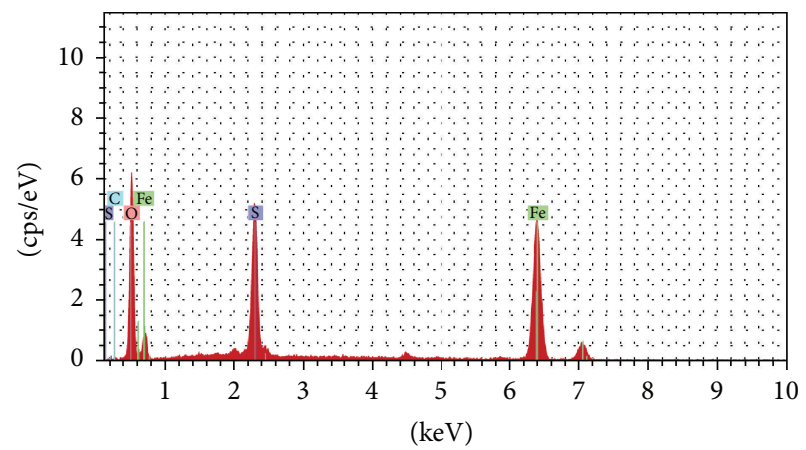

(b)

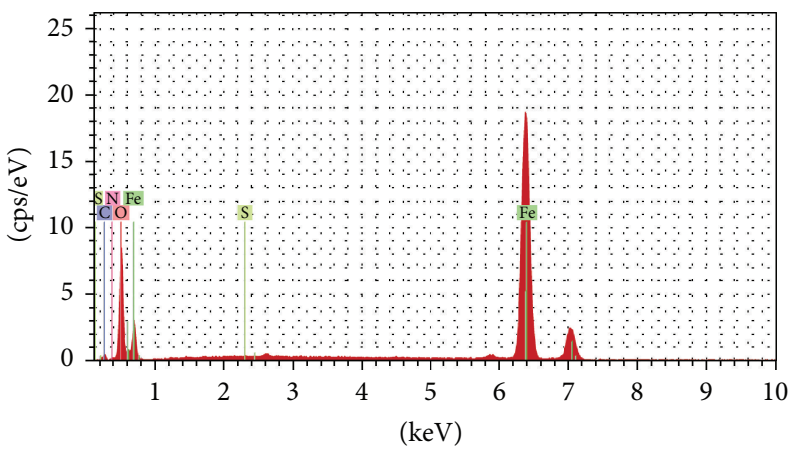

(c)

FIGURE 7: EDX images: (a) fresh mild steel, (b) mild steel in $\mathrm{H}_{2} \mathrm{SO}_{4}$, and (c) mild steel in $\mathrm{H}_{2} \mathrm{SO}_{4}$ with Nitroxoline.

TABLE 7: EDX elements analysis result of mild steel in $1 \mathrm{M}$ sulphuric acid in the absence and presence of Nitroxoline.

\begin{tabular}{|c|c|c|c|c|c|c|c|c|}
\hline Sample & $\mathrm{Fe}$ & $\mathrm{C}$ & $\mathrm{O}$ & $\mathrm{Mn}$ & $\mathrm{P}$ & $\mathrm{Cl}$ & $\mathrm{N}$ & $\mathrm{S}$ \\
\hline Fresh MS & 87.05 & 10.94 & 1.66 & 0.27 & 0.08 & - & - & - \\
\hline MS + sulphuric acid & 49.73 & 1.95 & 36.82 & - & - & - & - & 11.49 \\
\hline MS + sulphuric acid + inhibitor & 24.56 & 12.17 & 59.92 & - & - & - & 3.33 & 0.02 \\
\hline
\end{tabular}




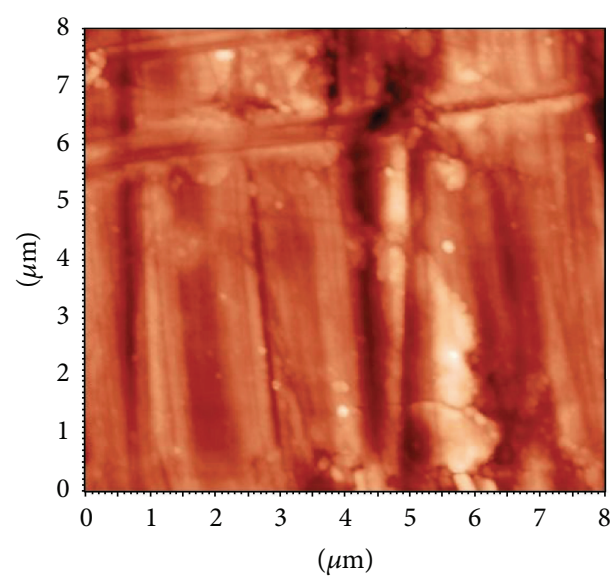

(a)
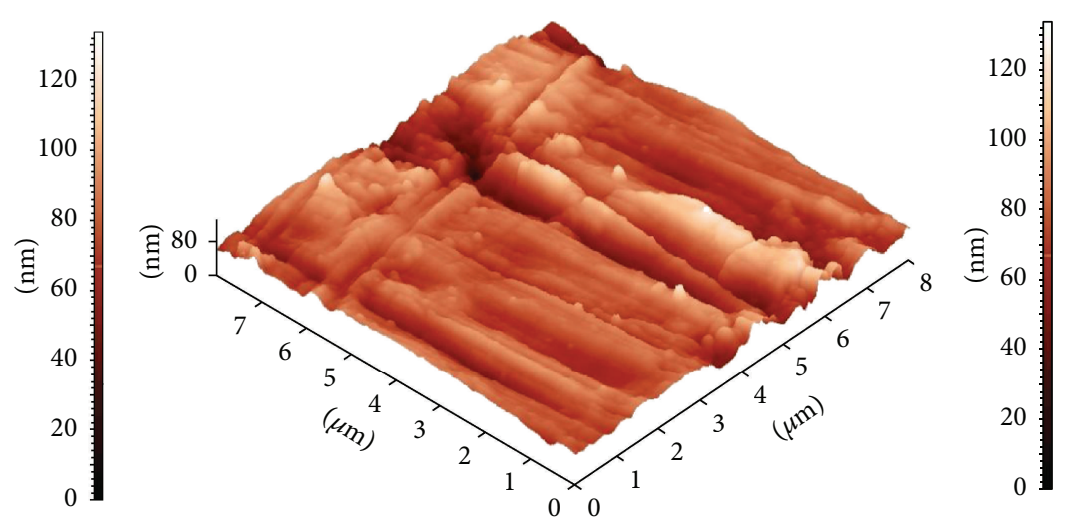

(b)

FIGURE 8: The topography AFM images of fresh mild steel: (a) two-dimensional structure and (b) three-dimensional structure.

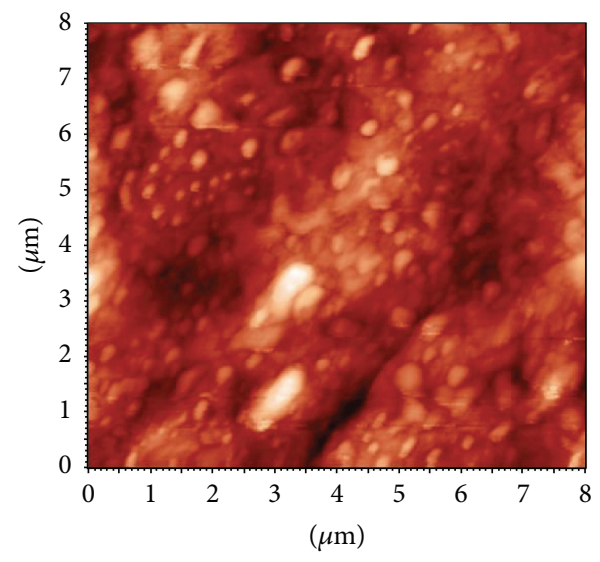

(a)
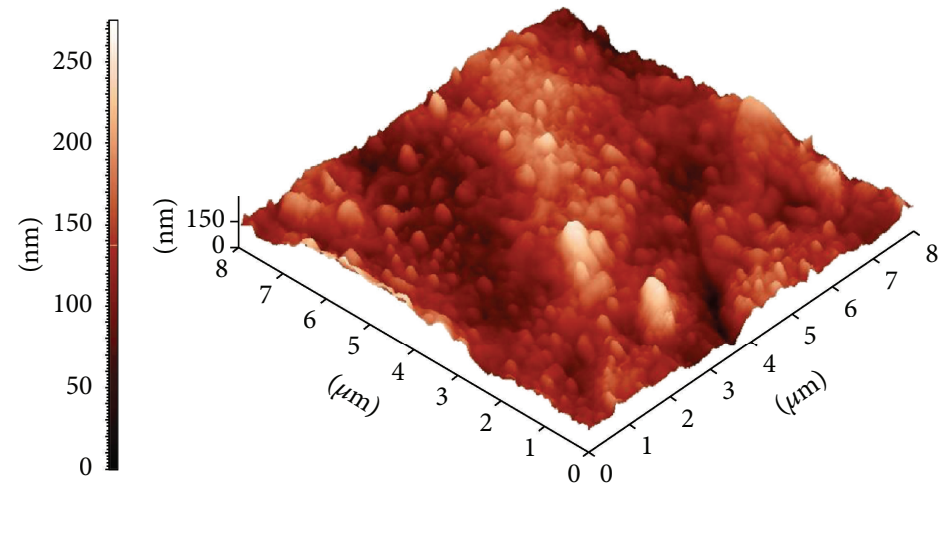

(b)

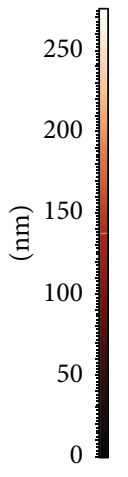

FIgURE 9: The topography AFM images of mild steel in $1 \mathrm{M} \mathrm{H}_{2} \mathrm{SO}_{4}$ : (a) two-dimensional structure and (b) three-dimensional structure.

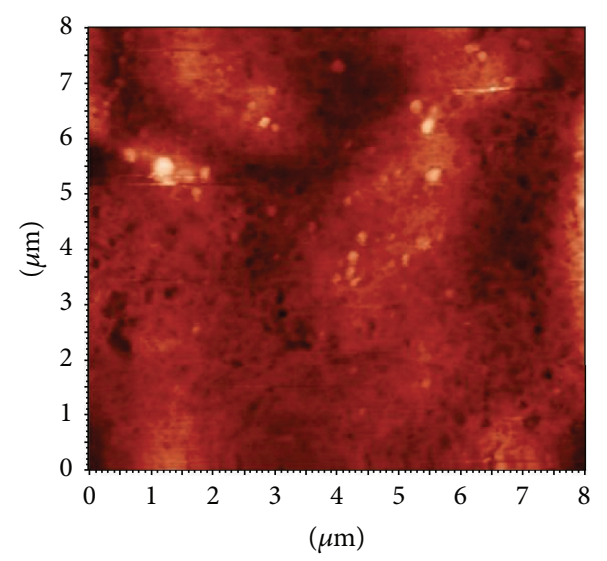

(a)
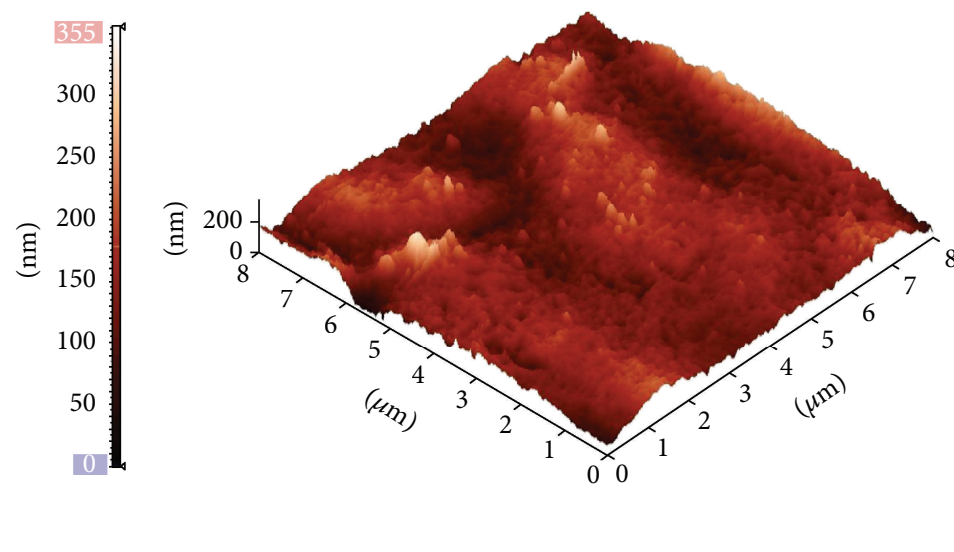

(b)

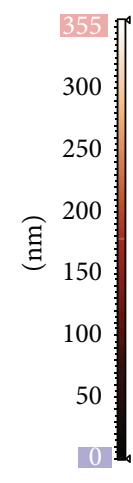

FIGURE 10: The topography AFM images of mild steel in $1 \mathrm{M} \mathrm{H}_{2} \mathrm{SO}_{4}$ with Nitroxoline: (a) two-dimensional structure and (b) three-dimensional structure. 
TABLE 8: AFM parameters obtained data for mild steel in the absence and the presence of Nitroxoline in $1 \mathrm{M}$ sulphuric acid.

\begin{tabular}{lcccc}
\hline Sample & $\begin{array}{c}\text { Root mean square } \\
\text { roughness }(\mathrm{nm})\end{array}$ & $\begin{array}{c}\text { Maximum peak-to-peak } \\
\text { height }(\mathrm{nm})\end{array}$ & $\begin{array}{c}\text { Ten-point height (nm) } \\
\text { Average roughness (nm) }\end{array}$ \\
\hline Fresh mild steel & 13.02 & 121.92 & 62.14 & 9.77 \\
MS in $1 \mathrm{M} \mathrm{H}_{2} \mathrm{SO}_{4}$ & 36.59 & 296.12 & 151.00 & 28.74 \\
MS in $1 \mathrm{M} \mathrm{H}_{2} \mathrm{SO}_{4}+$ Nitroxoline & 24.17 & 263.82 & 116.13 & 12.01 \\
\hline
\end{tabular}

\section{Competing Interests}

The authors declare that there is no conflict of interests regarding the publication of this paper.

\section{References}

[1] P. Muthukrishnan, B. Jeyaprabha, and P. Prakash, "Mild steel corrosion inhibition by aqueous extract of Hyptis suaveolens leaves," International Journal of Industrial Chemistry, vol. 5, no. 1, pp. 1-11, 2014.

[2] P. Mohan, R. Usha, G. P. Kalaignan, and V. S. Muralidharan, "Inhibition effect of benzohydrazide derivatives on corrosion behaviour of mild steel in $1 \mathrm{M} \mathrm{HCl,"} \mathrm{Journal} \mathrm{of} \mathrm{Chemistry,} \mathrm{vol.}$ 2013, Article ID 541691, 7 pages, 2013.

[3] R. Ganapathi Sundaram and M. Sundaravadivelu, "Anticorrosion activity of 8-quinoline sulphonyl chloride on mild steel in $1 \mathrm{M} \mathrm{HCl}$ solution," Journal of Metallurgy, vol. 2016, Article ID 8095206, 9 pages, 2016.

[4] B. E. Anitha Rani and B. B. J. Basu, "Green inhibitors for corrosion protection of metals and alloys: an overview," International Journal of Corrosion, vol. 2012, Article ID 380217, 15 pages, 2012.

[5] R. Ganapathi Sundaram, M. Sundaravadivelu, G. Karthik, and G. Vengatesh, "Inhibition effect of 4-hydroxyquinoline-2carboxylic acid on corrosion of mild steel in $1 \mathrm{M}$ sulphuric acid solution," Journal of Chemical and Pharmaceutical Research, vol. 7, no. 9, pp. 823-835, 2015.

[6] G. Achary, H. P. Sachin, Y. A. Naik, and T. V. Venkatesha, "The corrosion inhibition of mild steel by 3-formyl-8-hydroxy quinoline in hydrochloric acid medium," Materials Chemistry and Physics, vol. 107, no. 1, pp. 44-50, 2008.

[7] M. Abdallah, "Rhodanine azosulpha drugs as corrosion inhibitors for corrosion of 304 stainless steel in hydrochloric acid solution," Corrosion Science, vol. 44, no. 4, pp. 717-728, 2002.

[8] I. A. Raspini, "Influence of sodium salts of organic acids as additives on localized corrosion of aluminum and its alloys," Corrosion, vol. 49, no. 10, pp. 821-828, 1993.

[9] M. Lebrini, M. Lagrenée, H. Vezin, L. Gengembre, and F. Bentiss, "Electrochemical and quantum chemical studies of new thiadiazole derivatives adsorption on mild steel in normal hydrochloric acid medium," Corrosion Science, vol. 47, no. 2, pp. 485-505, 2005.

[10] O. Olivares, N. V. Likhanova, B. Gómez et al., "Electrochemical and XPS studies of decylamides of $\alpha$-amino acids adsorption on carbon steel in acidic environment," Applied Surface Science, vol. 252, no. 8, pp. 2894-2909, 2006.

[11] B. M. Prasanna, B. M. Praveen, N. Hebbar, T. V. Venkatesha, and H. C. Tandon, "Inhibition study of mild steel corrosion in $1 \mathrm{M}$ hydrochloric acid solution by 2-chloro 3-formyl quinoline," International Journal of Industrial Chemistry, vol. 7, no. 1, pp. 919, 2016.
[12] M. Behpour, A. M. Attaran, S. M. Ghoreishi et al., "Investigation of adsorption and inhibitive properties of some diamine compounds on mild steel corrosion in hydrochloric acid solution," Chemical Engineering Communications, vol. 201, no. 8, pp. 10771095, 2014.

[13] A. Sharmila, A. A. Prema, and P. A. Sahayaraj, "Influence of Murraya koenigii (curry leaves) extract on the corrosion inhibition of carbon steel in HCL solution," Rasayan Journal of Chemistry, vol. 3, no. 1, pp. 74-81, 2010.

[14] F. Bentiss, M. Traisnel, and M. Lagrenee, "Substituted 1,3,4oxadiazoles: a new class of corrosion inhibitors of mild steel in acidic media," Corrosion Science, vol. 42, no. 1, pp. 127-146, 2000.

[15] D. P. Schweinsberg, G. A. George, A. K. Nanayakkara, and D. A. Steinert, "The protective action of epoxy resins and curing agents-inhibitive effects on the aqueous acid corrosion of iron and steel," Corrosion Science, vol. 28, no. 1, pp. 33-42, 1988.

[16] R. Ganapathi Sundaram and M. Sundaravadivelu, "Electrochemical and surface investigation of quinoline-8-sulphonyl chloride as corrosion inhibitor for mild steel in acidic medium," International Journal of ChemTech Research, vol. 9, no. 3, pp. 527-539, 2016.

[17] K. Krishnaveni, J. Ravichandran, and A. Selvaraj, "Effect of Morinda tinctoria leaves extract on the corrosion inhibition of mild steel in acid medium," Acta Metallurgica Sinica (English Letters), vol. 26, no. 3, pp. 321-327, 2013.

[18] I. Ahamad, R. Prasad, and M. A. Quraishi, "Thermodynamic, electrochemical and quantum chemical investigation of some Schiff bases as corrosion inhibitors for mild steel in hydrochloric acid solutions," Corrosion Science, vol. 52, no. 3, pp. 933-942, 2010.

[19] K. Krishnaveni and J. Ravichandran, "Influence of aqueous extract of leaves of Morinda tinctoria on copper corrosion in $\mathrm{HCl}$ medium," Journal of Electroanalytical Chemistry, vol. 735, pp. 24-31, 2014.

[20] J. M. Bennett, J. Jahanmir, J. C. Podlesny, T. L. Balter, and D. T. Hobbs, "Scanning force microscope as a tool for studying optical surfaces," Applied Optics, vol. 34, no. 1, pp. 213-230, 1995.

[21] A. K. Singh and M. A. Quraishi, "Effect of Cefazolin on the corrosion of mild steel in $\mathrm{HCl}$ solution," Corrosion Science, vol. 52, no. 1, pp. 152-160, 2010. 

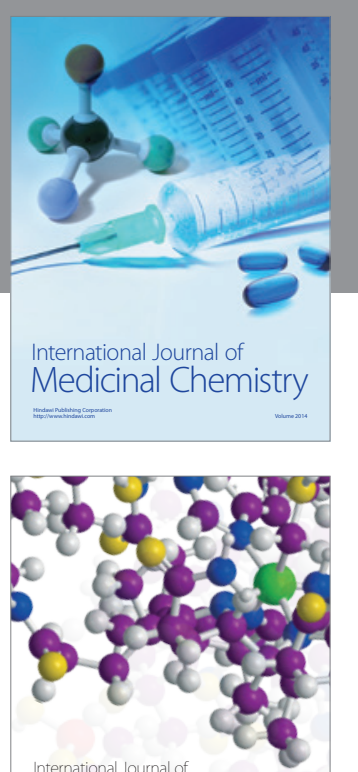

Carbohydrate Chemistry

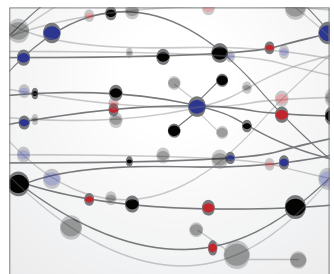

The Scientific World Journal
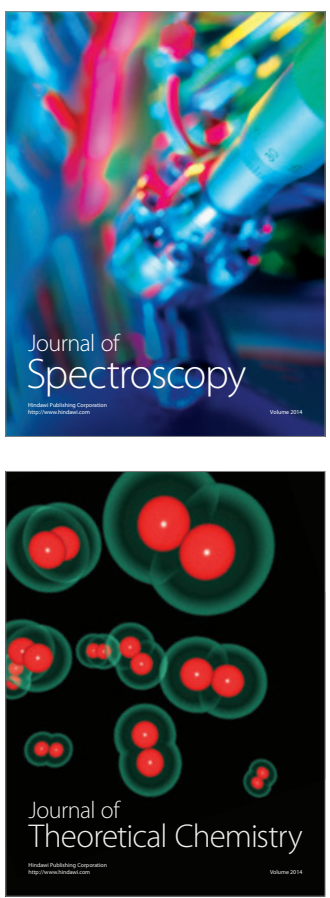
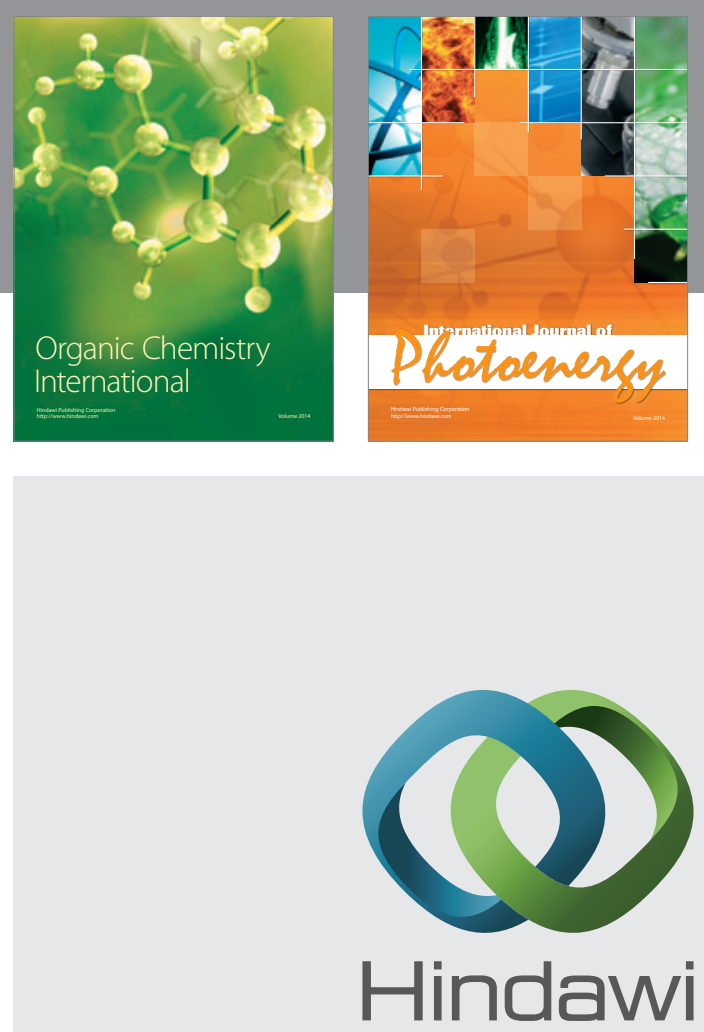

Submit your manuscripts at

http://www.hindawi.com

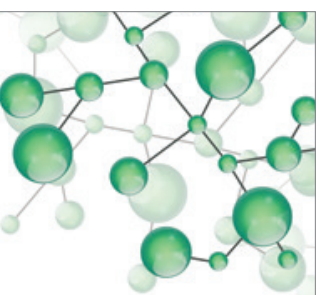

International Journal of

Inorganic Chemistry

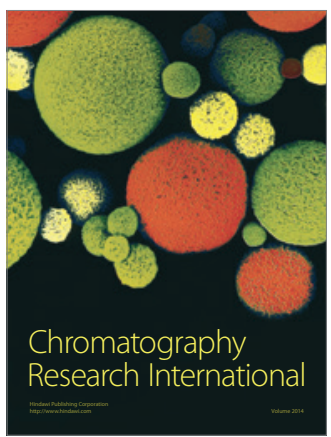

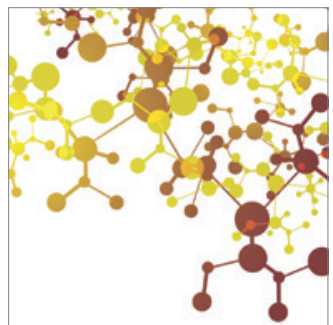

Applied Chemistry
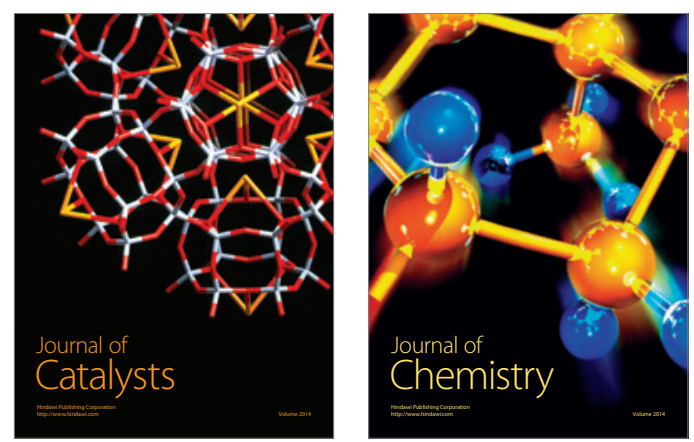
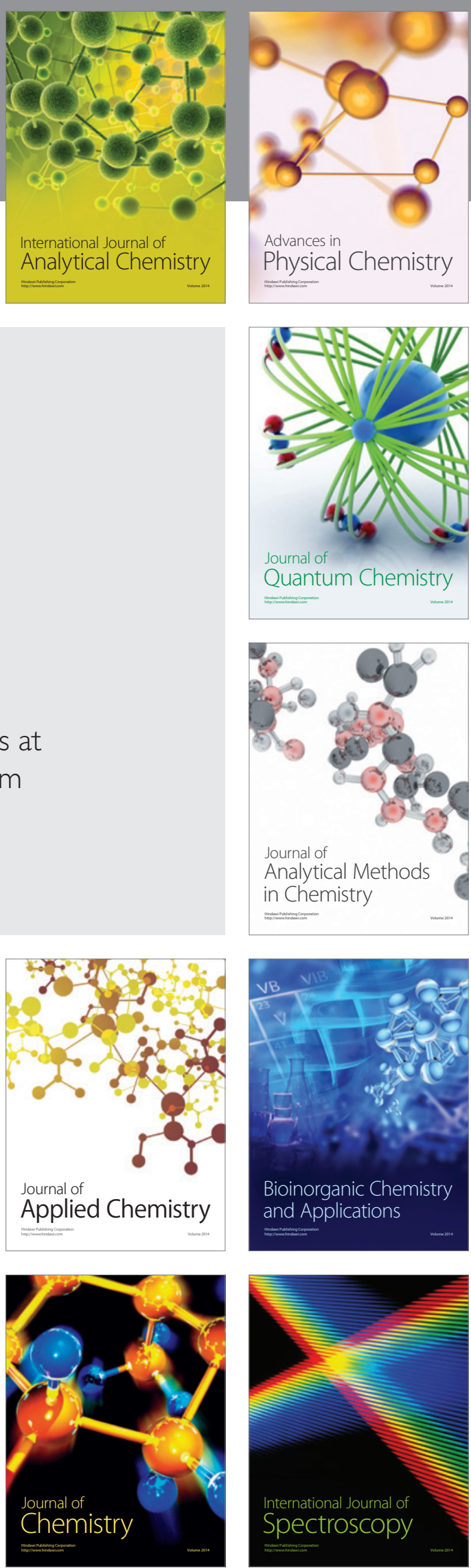